\title{
Binding of Metal Ions to Wool Keratin. I. Comparison of Binding Data by Gel Filtration and Equilibrium Dialysis
}

\author{
Satoru Kadokura, Takeaki MiYamoto, Hiraku ITo, and Hiroshi InAGAKI \\ Institute for Chemical Research, Kyoto University, \\ Uji, Kyoto 611, Japan.
}

(Received June 20, 1981)

\begin{abstract}
The binding of $\mathrm{Cu}(\mathrm{II})$ by keratin proteins extracted from wool in aqueous solution has been investigated by gel filtration and equilibrium dialysis in order to compare the binding data obtained by different methods. The gel filtration binding experiments were carried out on a Sephadex G-25 gel column using $0.05 \mathrm{M}$ acetate buffer as eluent in a pH range of $4.5-6.5$. The elution profiles of the $\mathrm{Cu}(\mathrm{II})$-keratin complexes were classical at equilibrium $\mathrm{Cu}(\mathrm{II})$-concentrations from 1 to $25 \mathrm{ppm}$ in the range of $\mathrm{pH}$ from 4.5 to 5.5. It was found that if the elution profile is classical, reliable binding data can be obtained by gel filtration with a simple technique. On the other hand, at a higher $\mathrm{pH}$ of 6.5 , anomalous elution profiles were observed; in addition to the classical peaks, a ghost peak with respect to the $\mathrm{Cu}(\mathrm{II})$-concentration appeared. Different mechanisms proposed for the appearance of the ghost peak by other authors were tested but failed to explain the present data. However, it was experimentally proved that the gel filtration data agreed with those of equilibrium dialysis if the $\mathrm{Cu}(\mathrm{II})$ exhibiting the ghost peak was independent of the binding by protein.
\end{abstract}

KEY WORDS Gel Filtration / Equilibrium Dialysis / Ghost Peak / Wool Keratin / Keratin-Cu(II) Complex /

A simple method for investigating the interaction between a small ligand* molecule and a macromolecule by gel filtration chromatography was first proposed by Hummel and Dreyer, ${ }^{1}$ and has been applied to studies on the binding of metal ions or peptides with proteins. ${ }^{2-11}$ This method may, in principle, be identified with equilibrium dialysis using a double-compartment system. Its merits are that the binding data can be obtained (i) without differentiating the free and bound ligands, (ii) with a small amount of sample, (iii) in a relatively short time, and (iv) with a simple technique, when certain experimental requirements are met. However, some anomalous phenomena in the elution profiles have been frequently reported: ghost peaks with respect to the ligand concentration. . $^{5,9,10,12,13}$

During the course of gel filtration studies on the binding of heavy metal ions by various keratin

* The term "ligand" in this paper is used for a small molecule which has positive interaction with the macromolecule in the system under study. derivatives from wool, we also observed a ghost peak in the elution profile of $\mathrm{Cu}$ (II)-keratin systems under certain experimental conditions. For systems which exhibit nonclassical ${ }^{13}$ elution profiles, it is desirable to compare the results obtained by gel filtration with those by the conventional equilibrium dialysis in order to investigate the advantages and limitations of the former method. However, most available data on the binding of ligands by macromolecules have been derived from either of these two methods, and no detailed comparison has so far been made between the experimental binding data obtained by gel filtration and equilibrium dialysis.

This paper deals with chromatographic anomalies observed in the elution profiles of $\mathrm{Cu}(\mathrm{II})-$ keratin systems and a comparison of the binding data obtained by these two methods. The results on the binding parameters of the $\mathrm{Cu}(\mathrm{II})$-keratin complexes and the structure of these complexes will be reported in subsequent papers. 


\section{S. KADOKURA et al.}

\section{GEL FILTRATION PROCEDURE OF HUMMEL AND DREYER}

There are two principal requirements for gels to be used in studying interaction between ligand and macromolecule. One is that the gel pores be freely accessible to unbound ligands but able to exclude macromolecule species. The other is that there must be no adsorption of macromolecules or their complexes onto the gel. The interaction of the ligand with the gel does not interfere with the evaluation of results, according to the theories for the ligand binding by macromolecules. ${ }^{14-16}$

The gel filtration experiment involves the following three processes: (i) the column is equilibrated with an eluent containing the ligand of known concentration, (ii) the sample macromolecule dissolved in the eluent is injected into the column, and (iii) the elution is continued until expected peaks appear. As the macromolecules flow through the column, the ligands bind to the macromolecules until equilibrium is reached with respect to the ligand concentration in the eluent. Subsequently, the macromolecule and its complexes emerge from the void volume of the column, giving a positive peak both in the plots of ligand and macromolecule concentrations versus elution volume, and then a negative peak in the elution profile of the ligand, i.e., a trough reflecting the amount of ligand removed from the eluent. Usually, the trough is relatively broad, because it spreads out as a result of axial dispersion in the column. However, the amount of ligand bound to the macromolecule, indicated by the positive peak, should be equal to that of ligand removed from the eluent. If the experimental conditions are appropriate, both positive and negative peaks of the ligand should be observed separately. In addition, the two base-line concentrations in the elution curve just after the positve peak and the trough should be identical and correspond to the original ligand concentration in the eluent. The appearance of a plateau between the peak and the trough provides a simple criterion for the attainment of equilibrium in the column. ${ }^{2}$

\section{EXPERIMENTAL}

\section{Materials}

Salts and buffer materials were all of analytical grade and used without further purification.
Deionized water was used throughout. A standard aqueous solution of $\mathrm{CuCl}_{2}$ with a concentration of $1000 \mathrm{ppm}$ was obtained from Nakarai Chemical Co., Kyoto. A standard aqueous solution of $\mathrm{Cu}\left(\mathrm{ClO}_{4}\right)_{2}$ was prepared from $\mathrm{Cu}\left(\mathrm{ClO}_{4}\right)_{2} \cdot 6 \mathrm{H}_{2} \mathrm{O}$.

The high-sulfur protein fraction, which is one of the major constituents of soluble proteins from wool, ${ }^{17}$ was used for the present study. Its $S$ carboxymethylated derivative was prepared from reduced wool (Merino 64's), according to the procedure of Dowling and Crewther, ${ }^{18}$ and is hereafter denoted as $\mathrm{WCOOH}$. This procedure includes extraction of the wool with 2-mercaptoethanol at $\mathrm{pH}$ 10.5 in the presence of $8 \mathrm{M}$ urea, alkylation of the extracted proteins with iodoacetic acid, and isolation from the low-sulfur protein fraction at $\mathrm{pH} 4.4$ in the presence of $0.5 \mathrm{M} \mathrm{KCl}$. The sample $\mathrm{WCOOH}$ dissolved in a potassium acetate buffer was dialyzed against deionized water and then freeze-dried.

The $\gamma$-keratose $\left(\mathrm{WSO}_{3} \mathrm{H}\right)$, a high-sulfur protein fraction from oxidized wool, was prepared from performic acid-oxidized wool (Merino 64's), according to the method of Corfield et al ${ }^{19}$

\section{Gel Filtration Binding Experiments}

A series of gel filtration binding experiments were carried out in a $\mathrm{pH}$ range of $4.5-6.5$, using a Sephadex G-25 column $(1.1 \times 50 \mathrm{~cm})$ equipped with a thermostated water jaket. Unless otherwise stated, the column was equilibrated with $0.05 \mathrm{M}$ acetate buffer containing the desired concentration of $\mathrm{Cu}(\mathrm{II})$ and $0.1 \mathrm{M} \mathrm{KCl}$. Some experiments were performed in $0.05 \mathrm{M}$ acetate buffer containing $0.1 \mathrm{M} \mathrm{NaClO}_{4}$, instead of $0.1 \mathrm{M} \mathrm{KCl}$. The sample keratin was dissolved in the buffer used for equilibration of the column. One $\mathrm{ml}$ of $1-2 \%$ sample solution was applied to the column and eluted at $20^{\circ} \mathrm{C}$ with the same buffer as that used for equilibration. The effluent was collected by a fraction collector on a weight basis to obtain $3 \mathrm{~g}$ for each fraction. The elution was carried out by gravitational force at a flow rate of $c a .90 \mathrm{ml} \mathrm{h}^{-1}$. The time required for each chromatographic run was approximately $3 \mathrm{~h}$.

The $\mathrm{pH}$ was adjusted with a relatively concentrated solution of $\mathrm{KCl}$ or $\mathrm{HCl}$ to prevent appreciable volume change. The keratin concentration of the fraction was estimated from the absorbance at $278 \mathrm{~nm}$ by a Shimadzu UV-200S spectrophotometer, and the concenration of $\mathrm{Cu}(\mathrm{II})$ by a 
Shimadzu Model AA-610S atomic absorption spectrometer. The equilibrium $\mathrm{Cu}(\mathrm{II})-$ concentration was not corrected for the formation of the $\mathrm{Cu}(\mathrm{II})$-acetate complex in the acetate buffer, ${ }^{5}$ so that the total concentration in the elution buffer was equated to the equilibrium $\mathrm{Cu}(\mathrm{II})$-concentration.

\section{Equilibrium Dialysis}

A visking cellophane tubing was thoroughly rinsed with deionized water and immersed in the buffer used for equilibrium dialysis for $24 \mathrm{~h}$. A cellophane tubing sack containing $10 \mathrm{ml}$ of the sample solution was equilibrated with $90 \mathrm{ml}$ of the external solution at $20^{\circ} \mathrm{C}$ for 2 days. Preliminary experiments showed that it took 2 days for the attainment of dialysis equilibrium and that the amount of $\mathrm{Cu}(\mathrm{II})$ bound to the cellophane was negligible.

\section{RESULTS AND DISCUSSION}

\section{Elution Profiles at $p H 4.5$ and 5.5}

Figure 1 shows a typical elution profile obtained for the system $\mathrm{Cu}(\mathrm{II})-\mathrm{WCOOH}$ on a Sephadex G25 column at $\mathrm{pH} 5.5$ and $20^{\circ} \mathrm{C}$. As can be seen from the figure, a positive peak for $\mathrm{Cu}(\mathrm{II})$ eluted immediately after the void volume of the column appear in the same retention range as that for a UV absorption peak associated with the protein component. This indicates that the positive peak for $\mathrm{Cu}$ (II) is caused by the WCOOH-bound $\mathrm{Cu}(\mathrm{II})$. Consequently, the negative peak for $\mathrm{Cu}(\mathrm{II})$, i.e., a relative broad trough, reflects the amount of $\mathrm{Cu}(\mathrm{II})$ removed from the eluent. In fact, the areas of both

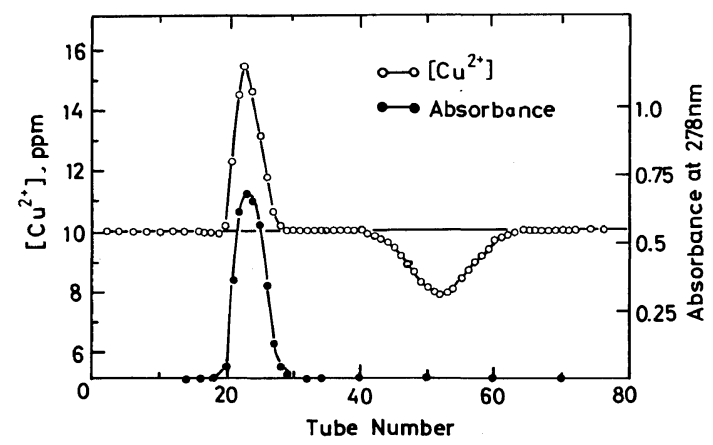

Figure 1. A typical elution profile of the system $\mathrm{Cu}$ (II)-WCOOH on a Sephadex G-25 column at $\mathrm{pH} 5.5$ and $20^{\circ} \mathrm{C}$. Eluent, $0.05 \mathrm{M}$ acetate buffer containing $10 \mathrm{ppm}$ of $\mathrm{Cu}(\mathrm{II})$ and $0.1 \mathrm{M} \mathrm{KCl}$. peaks were equal within experimental error, which suggests that there occurred no adsorption of keratin and its $\mathrm{Cu}(\mathrm{II})$-complexes onto the Sephadex gel used. Moreover, the UV absorption peak convinced us that the sample recovery was approximately $100 \%$. From these findings, we drew the following conclusions. The presence of protein little interferes with the determination of $\mathrm{Cu}(\mathrm{II})$ concentration by atomic absorption spectrometry, and the equilibrium is attained throughout the eluting system as can be confirmed by the base-lines in Figure 1, so that the rate of complex formation of keratin with $\mathrm{Cu}$ (II) is rapid enough in comparison with that of sample transport through the column.

Similar classical $^{13}$ elution profiles were obtained at equilibrium $\mathrm{Cu}(\mathrm{II})$-concentrations from 1 to 25 $\mathrm{ppm}$ and at $\mathrm{pH}$ from 4.5 to 5.5. At equilibrium $\mathrm{Cu}(\mathrm{II})$-concentrations lower than $1 \mathrm{ppm}$, the negative peaks were too broad to determine their areas accurately. However, it was possible to calculate the

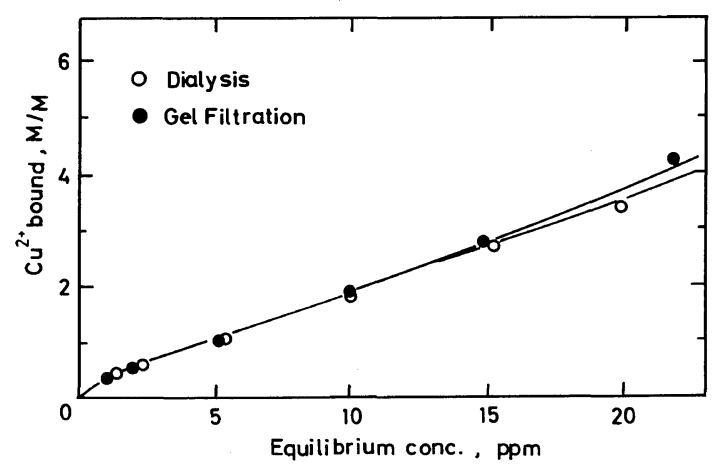

Figure 2. Comparison between the binding isotherms obtained by equilibrium dialysis $(\mathrm{O})$ and gel filtration (O) for the system $\mathrm{Cu}(\mathrm{II})-\mathrm{WCOOH}$ at $\mathrm{pH} 5.5$.

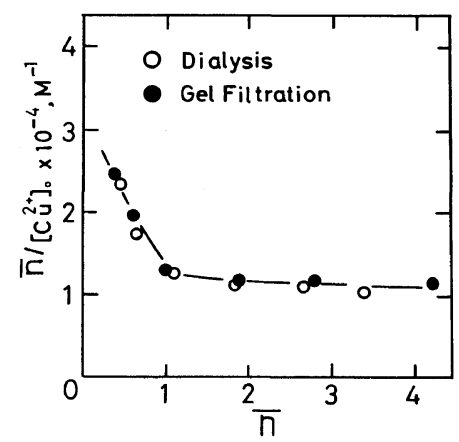

Figure 3. Scatchard plots of the binding data in Figure 2. 


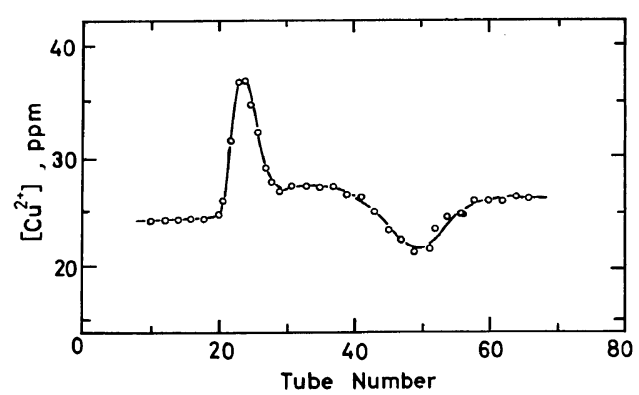

Figure 4. Elution profile of the system $\mathrm{Cu}(\mathrm{II})$ WCOOH on a Sephadex G-25 column at pH 5.5 and $20^{\circ} \mathrm{C}$. Eluent, $0.05 \mathrm{M}$ acetate buffer containing $27 \mathrm{ppm}$ of $\mathrm{Cu}(\mathrm{II})$ and $0.1 \mathrm{M} \mathrm{KCl}$.

amount of keratin-bound $\mathrm{Cu}(\mathrm{II})$ from the area under the sharp positive peak of $\mathrm{Cu}(\mathrm{II})$.

Figure 2 compares the binding isotherm for the system $\mathrm{Cu}(\mathrm{II})-\mathrm{WCOOH}$ at $\mathrm{pH} 5.5$ obtained by gel filtration with that by equilibrium dialysis. In Figure 3, these binding data are examined according to the relation proposed by Scatchard, ${ }^{14}$

$$
\frac{\bar{n}}{[\mathrm{M}]_{0}}=K(n-\bar{n})
$$

where $\dot{n}$ is the amount in mol of the bound ligand per mol of macromolecule, $n$ the number of binding sites, $K$ the binding constant and $[\mathrm{M}]_{0}$ the concentration of the free ligand. The two Scatchard plots derived from the different methods are quantitatively in good agreement with each other. The data points in the figure cannot be fitted by a straight line but follow a curve characteristic of a macromolecular species having more than two classes of independent binding sites with different binding constants. The binding parameters, i.e., the binding constant and the number of binding sites, may be estimated from such a binding curve using a procedure similar to that described by Price, ${ }^{6}$ and will be reported elsewhere. ${ }^{21}$

Differing from those reported so far, the elution profiles we observed were unusual at equilibrium $\mathrm{Cu}$ (II)-concentrations higher than $25 \mathrm{ppm}$; the plateau between the positve and negative peaks appeared on a level different from the original baseline, as shown in Figure 4. However, the reason for this is still unclear.

\section{Chromatographic Anomalies at pH 6.5}

At a high $\mathrm{pH}$ value of 6.5 , we obtained anom-

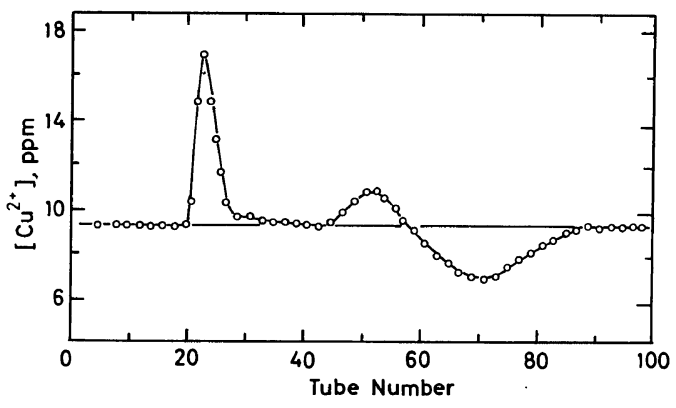

(a)

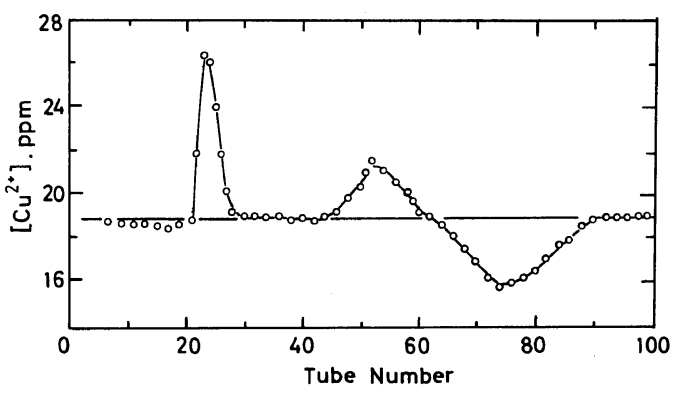

(b)

Figure 5. Anomalous elution profiles observed for the system $\mathrm{Cu}(\mathrm{II})-\mathrm{WSO}_{3} \mathrm{H}$ on a Sephadex G-25 column at $\mathrm{pH}$ 6.5. Eluent, $0.05 \mathrm{M}$ acetate buffer containing $0.1 \mathrm{M}$ $\mathrm{KCl}$. The equilibrium $\mathrm{Cu}(\mathrm{II})$-concentration are 9.5 (a) and $18.6 \mathrm{ppm}(\mathrm{b})$, respectively.

alous profiles distinctly different from those at $\mathrm{pH}$ 4.5 and 5.5. Figures 5a and 5b show two examples of such elution profiles obtained for the system $\mathrm{Cu}(\mathrm{II})-\mathrm{WSO}_{3} \mathrm{H}$. We can see that, in addition to the normal positive peak, an additional ghost peak with respect to the $\mathrm{Cu}$ (II) concentration appeared just prior to the trough of $\mathrm{Cu}(\mathrm{II})$. These nonclassical elution profiles were observed even in a $\mathrm{Cu}(\mathrm{II})$ concentration range in which classical elution profiles had been obtained at $\mathrm{pH} 4.5$ and 5.5. The area of the ghost peak increased with increasing concentration of $\mathrm{Cu}(\mathrm{II})$. It was found that the sum of two positive peak areas was almost the same as that of the trough. No difference in UV/visible absorption was observed between the plateau and the ghost peak.

In the gel filtration, the free $\mathrm{Cu}(\mathrm{II})$-concentration in the buffer in the early stage of a chromatographic run was less than that required to equilibrate the column. However, there is no doubt that equilibrium was attained, as has already been mentioned, and the appearance of the ghost peak should not be 
attributed to the variation in free $\mathrm{Cu}(\mathrm{II})$-concentration.

In the present system, the binding experiments were carried out in an acetate buffer to prevent the change in $\mathrm{pH}$ as the sample traversed the column. Hence, the ghost peak may possibly be affected by the buffer anion concentration, since it is a known fact that $\mathrm{Cu}$ (II) interacts with acetate anion to form $\mathrm{Cu}(\mathrm{II})$-acetate complex. ${ }^{5}$ However, our experiments showed that the ghost peak becomes more distinctive as the acetate concentration in the buffer decreases from 0.05 to $0.01 \mathrm{M}$. Furthermore, the same ghost peak as in the acetate buffer was observed in an $N$-ethylmorpholine buffer $(0.05 \mathrm{M}$ $\mathrm{N}$-ethylmorpholine- $\mathrm{HCl}$ ), for which $\mathrm{N}$-ethylmorpholine interacts but little with $\mathrm{Cu}(\mathrm{II}){ }^{5}$ These results suggest that the appearance of the ghost peak cannot be interpreted in terms of the attractive interaction between the acetate anion and $\mathrm{Cu}(\mathrm{II})$.

On the other hand, the buffers used contained $\mathrm{KCl}$ at a relatively high ionic strength, namely $0.1 \mathrm{M}$, in order to reduce the Donnan equilibrium effect. Thus, we examined the effects of the ionic strength and the kind of anion in the buffer on the appearance of the ghost peak by changing the concentration of $\mathrm{KCl}$ from 0.1 to $0.01 \mathrm{M}$ and by replacing $\mathrm{Cl}^{-}$by $\mathrm{ClO}_{4}{ }^{-}{ }^{20}$ We found that the $\mathrm{KCl}$ concentration and the type of anion had little effect on the appearance of the ghost peak.

The appearance of the ghost peak has been interpreted in two ways. ${ }^{5,13}$ One is that for a system containing two ligands, the peak appears when a fraction of either ligand attached to the macromolecule in advance is replaced by the other ligand during the elution. ${ }^{5}$ The other is that for a system in which some ligand-mediated association of macromolecule occurs, the ghost peak is expected to appear when a fraction of the ligand is released from the macromolecule by a decrease in the macromolecule concentration during the elution. ${ }^{13}$ This prediction was made by computer simulation.

Now, it is obvious that the ghost peak found in our system cannot be explained in the former way, since the system contains no competitor ligand to interact negatively with $\mathrm{Cu}(\mathrm{II})$. On the other hand, the latter way appears to be pertinent for our observation since our profile including the ghost peak is quite similar to that predicted by the aforementioned computer simulation..$^{13}$ However, we found no symptom for any ligand-mediated

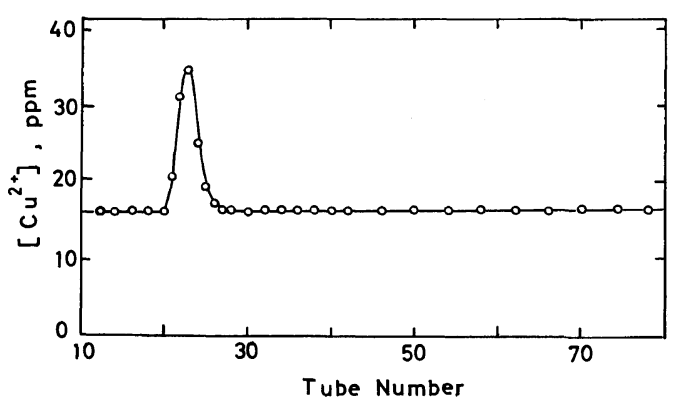

Figure 6. Elution profile of the system $\mathrm{Cu}(\mathrm{II})-\mathrm{WSO}_{3} \mathrm{H}$ on a Sephadex G-25 column at pH 6.5 and $20^{\circ} \mathrm{C}$. Eluent, $0.05 \mathrm{M}$ acetate buffer containing $16.5 \mathrm{ppm}$ of $\mathrm{Cu}(\mathrm{II})$ and $0.1 \mathrm{M} \mathrm{KCl}$. Column loaded with sample solution previously dialyzed against the eluent.

association of the macromolecule in our system.

Further, to discuss the appearance of ghost peak we did another experiment described below. Before the elution experiment, we dialyzed a sample keratin solution, whose concentration and $\mathrm{pH}$ were the same as those for the elution experiment, against a large amount of the elution buffer for two days. The keratin solution was then subjected to the elution experiment using the above elution buffer. It was found that the ghost peak disappeared even for the system adjusted at pH 6.5, as shown in Figure 6. This result shows that the appearance of the ghost peak cannot be attributed to a decrease in the concentration of keratin and its complexes with $\mathrm{Cu}(\mathrm{II})$ during the elution; our system is not a ligandmediated associating one. Note that the negative peak also disappeared as a result of the dialysis.

Before we go into a detailed discussion of the above result, we will now analyze two series of binding data obtained by the different methods. Figure 7 shows the binding isotherms found for the system $\mathrm{Cu}(\mathrm{II})-\mathrm{WSO}_{3} \mathrm{H}$ at $\mathrm{pH}$ 6.5, which exhibit nonclassical elution profiles. Curve-A in the figure was obtained from the binding data obtained by gel filtration by estimating the amount of bound $\mathrm{Cu}(\mathrm{II})$ as the sum of the areas of the first and the ghost peaks. On the other hand, Curve-B was constructed from the data obtained by equilibrium dialysis and distinctly differs from Curve-A. However, we found that the gel filtration data gave Curve-B when the amount of bound $\mathrm{Cu}(\mathrm{II})$ was estimated only from the first peak, as shown by the filled circles in Figure 7. In this connection, it should be mentioned that 


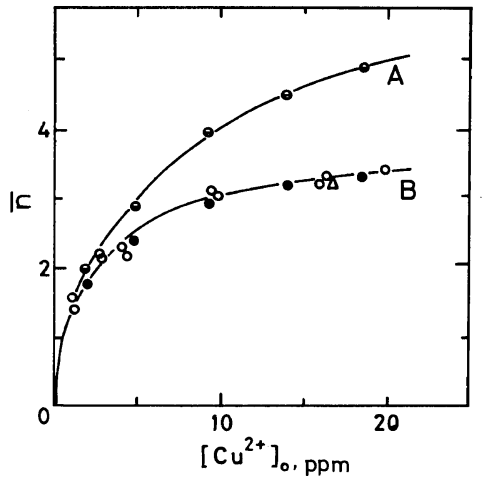

Figure 7. Binding isotherms obtained for the system $\mathrm{Cu}(\mathrm{II})-\mathrm{WSO}_{3} \mathrm{H}$ at $\mathrm{pH}$ 6.5: $\bigcirc$, equilibrium dialysis; $\ominus$, calculated from the sum of two positive peaks: calculated from only the first peak; $\triangle$, derived from the experiment shown in Figure 6.

the data point shown by a triangle derived from the curve shown in Figure 6 falls on Curve-B.

From these findings, we may conculude that the binding parameters drived from gel filtration can be identified with those from equilibrium dialysis even for elution systems showing the ghost peak. However, we are as yet unable to explain the reason why the ghost peak appears. Finally we point out that the ghost peak was much more pronounced for $\mathrm{WSO}_{3} \mathrm{H}$ than for $\mathrm{WCOOH}$; these are polyelectrolytes strong and weak, respectively.

\section{REFERENCES}

1. J. P. Hummel and W. J. Dreyer, Biochim. Biophys.
Acta, 63, 530 (1962).

2. G. F. Fairclough, Jr. and J. S. Fruton, Biochemistry, 5, 673 (1966).

3. S. E. Bryan and E. Frieden, Biochemistry, 6, 2728 (1967).

4. A. W. Girotti and E. Breslow, J. Biol. Chem., 243, 216 (1969).

5. E. Breslow and A. W. Girotti, J. Biol. Chem., 245, 1527 (1970).

6. P. A. Price, J. Biol. Chem., 247, 2895 (1972).

7. A. Klarman, N. Shalkai, and E. Daniel, Biochim. Biophys. Acta, 257, 150 (1972).

8. R. F. Colman, Anal. Chem., 46, 358 (1972).

9. A. Levi, M. Cimino, D. Mercanti, and P. Calissano, Biochim. Biophys. Acta, 365, 450 (1974).

10. J. C. Lee, D. Harrison, and S. N. Timasheff, J. Biol. Chem., 250, 9276 (1975).

11. S. Kadokura, T. Miyamoto, and H. Inagaki, Biopolymers, 20, 1113 (1981).

12. N. Yoza, J. Chromatogr., 86, 325 (1973).

13. J. R. Cann and N. Hinman, Biochemistry, 15, 4614 (1976).

14. G. Scatchard, Ann. N.Y. Acad. Sci., 51, 660 (1949).

15. I. M. Klotz and D. L. Hunstone, Biochemistry, 10, 3065 (1971).

16. G. Schwarz, Eur. J. Biochem., 12, 442 (1970).

17. W. G. Crewther, R. D. B. Fraser, F. G. Lennox, and H. Lindley, Adv. Protein Chem., 20, 191 (1965).

18. L. M. Dowling and W. G. Crewther, Prep. Biochem., 4, 203 (1974).

19. M. C. Corfield, A. Robson, and B. Skinner, Biochem. J., 68, 348 (1958).

20. S. Kokot, M. Feughelman, and R. M. Golding, Text. Res. J., 42, 704 (1972).

21. S. Kadokura, H. Ito, T. Miyamoto, and H. Inagaki, Kobunshi Ronbunshu, 38, 419 (1981). 